\title{
Nox4 is involved in high glucose-induced apoptosis in renal tubular epithelial cells via Notch pathway
}

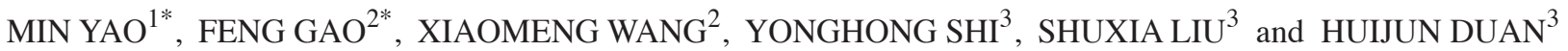 \\ ${ }^{1}$ Department of Biochemistry, Hebei Medical University, Shijiazhuang, Hebei 050017; \\ ${ }^{2}$ Department of Pathology, The Third Hospital of Hebei Medical University, Shijiazhuang, Hebei 050051; \\ ${ }^{3}$ Department of Pathology, Hebei Medical University, Shijiazhuang, Hebei 050017, P.R. China
}

Received February 28, 2016; Accepted February 22, 2017

DOI: $10.3892 / \mathrm{mmr} .2017 .6516$

\begin{abstract}
It has previously been demonstrated that nicotinamide adenine dinucleotide phosphate-oxidase (NADPH) oxidase 4 (Nox4), is important in the pathogenesis of diabetic nephropathy (DN), however the exact mechanisms remain to be elucidated. The present study aimed to examine the effect of Nox 4 on the alteration of the Notch pathway and cell apoptosis in the renal tubular epithelial cell line, HKC, under conditions of high glucose (HG; $30 \mathrm{mmol} / 1$ glucose). Nox4 and the Notch pathway were inhibited by $\mathrm{N}$-acetylcysteine (NAC), diphenylene iodonium (DPI) or $\gamma$-secretase inhibitor (DAPT). The protein levels of Nox4, Notch1, Notch intracellular domain 1 (NICD1), phosphorylated (p) Ras-related C3 botulinum toxin substrate 1 (Rac1), Rac1, B-cell lymphoma 2 apoptosis regulator (Bcl-2), $\mathrm{Bcl}-2$ associated protein $\mathrm{X}$ apoptosis regulator (Bax) and cleaved caspase-3 were determined by western blotting. The Nox4 and Notch1 mRNA levels were detected by reverse transcription-quantitative polymerase chain reaction. Intracellular reactive oxygen species (ROS) levels were detected via chloromethyl-2',7'-dichlorodihydrofluorescein diacetate. Apoptotic cells were determined using an Annexin V/propidium iodide apoptosis detection kit. HG upregulated Nox4, Notch1, NICD1, p-Rac1, Bax and cleaved caspase-3 expression levels and downregulated Bcl-2 expression in cultured HKC cells, compared with cells cultured in normal glucose levels. Inhibition of the Notch pathway via DAPT increased Bcl-2 expression, decreased Bax and cleaved caspase-3 levels and prevented HKC cell apoptosis. Inhibition of Nox4 by NAC and DPI inhibited the Notch signaling pathway and ROS generation,
\end{abstract}

Correspondence to: Professor Huijun Duan, Department of Pathology, Hebei Medical University, 361 Zhongshan East Road, Shijiazhuang, Hebei 050017, P.R. China

E-mail: duanhj999@163.com

*Contributed equally

Key words: high glucose, nicotinamide adenine dinucleotide phosphate-oxidase oxidase 4, Notch pathway, renal tubular epithelial cell, apoptosis which prevented HKC cell apoptosis. These findings indicated that Nox4 potentially mediates HG-induced HKC cell apoptosis via the Notch pathway, and may be involved in renal tubular epithelial cell injury in DN.

\section{Introduction}

Diabetic nephropathy (DN) is a frequently occurring type of progressive kidney disease that develops in the diabetic population. Reactive oxygen species (ROS) have been revealed as important signaling molecules that mediate renal injury in patients with diabetes (1). High glucose (HG) increases intracellular ROS levels in renal cells and contributes to the development and progression of diabetic renal injury $(2,3)$. Under normal physiological conditions, low levels of ROS are produced by the nicotinamide adenine dinucleotide phosphate-oxidase (NADPH) oxidase (Nox) family as byproducts of the mitochondrial electron transport chain, and are important in the regulation of various cellular functions including inflammatory gene expression, proliferation and apoptosis (4). The Nox family are membrane bound enzymatic complexes and structural homologues of phagocytic Nox (gp91 phox/Nox2) and are categorized as follows: Nox1-Nox5 and Dual oxidase Duox proteins 1 and 2 (5). All Nox subunits have been reported to bind $\geq 1$ regulatory subunits, including $\mathrm{p} 22^{\text {phox }}$ which is localized in the membrane, cytosolic submits $\mathrm{p} 40^{\text {phox }}, \mathrm{p} 47^{\text {phox }}$, p67 ${ }^{\text {phox }}$ and Ras-related C3 botulinum toxin substrate (Rac) GTPases (5). Various studies have demonstrated that the translocation and binding of $\mathrm{p} 47^{\mathrm{phox}}$ to Nox and the participation of Rac are key steps in the activation of Nox and the generation of ROS (6). Nox4 is a critical ROS-generating complex, expressed in the kidney $(5,6)$.

It has previously been demonstrated that the Notch pathway is involved in the occurrence of DN and various other kidney diseases (7). In mammals, the Notch pathway consists of four receptors (Notch1-4) and five ligands, termed Jagged1, Jagged2, Delta-like ligand (D11) 1, D113 and Dll4. The interaction of these ligands with the Notch receptors results in receptor conformational changes, subsequent $\gamma$-secretase mediated proteolysis and release of Notch intracellular domain (NICD), which on transfer to the nucleus, activates gene transcription of Hes family basic helix-loop-helix (BHLH) transcription factor (Hes) 1 and Hes related family BHLH transcription 
factor with YRPW motif 1 (8). The Notch signaling pathway is important in differential gene expression and influences cell differentiation, proliferation and apoptosis $(9,10)$.

Yan et al (11) demonstrated that transforming growth factor- $\beta$ (TGF- $\beta$ ) triggers apoptosis in human cultured endothelial cells, an effect dependent on the overexpression of Nox4 and production of ROS via modulation of p38 and Notch pathways. However, it has not yet been revealed whether Nox4 regulates renal tubular epithelial cell apoptosis via the Notch pathway in DN. Previous studies have demonstrated that HG affects normal physical metabolism and function of tubular cells, inducing cell apoptosis (12). In the present study, the HG-induced human renal proximal tubular cell line (HKC) was selected to detect and evaluate the functional activity of Nox4, the Notch signaling pathway and cell apoptotic rate under HG conditions. In addition, Nox4 and the Notch pathway were chemically inhibited in order to further explore the mechanism of tubular cell apoptosis.

\section{Materials and methods}

Cell culture. HKC cells were obtained from the cell resource center at Peking Union Medical College (Beijing, China) and cultured in Dulbecco's modified Eagle's medium (DMEM; Gibco; Thermo Fisher Scientific, Inc., Waltham, MA, USA), supplemented with $10 \%$ fetal bovine serum (FBS; Gibco; Thermo Fisher Scientific, Inc.) at $37^{\circ} \mathrm{C}$ in an environment containing $5 \% \mathrm{CO}_{2}$. HKC cells were grown to $70 \%$ confluence and synchronized in serum-free DMEM for $24 \mathrm{~h}$, then stimulated with normal glucose (NG; $5.5 \mathrm{mmol} / \mathrm{l} \mathrm{D-Glucose}$; Sigma-Aldrich; Merck KGaA, Darmstadt, Germany), HG (30 mmol/1 D-Glucose), HG plus $\gamma$-secretase inhibitor (DAPT; $1 \mu \mathrm{mol} / \mathrm{l}$ ), HG plus $\mathrm{N}$-acetylcysteine (NAC; $5 \mathrm{mmol} / \mathrm{l}$ ) or HG plus diphenylene iodonium (DPI; $5 \mu \mathrm{mol} / \mathrm{l}$ ) all from Sigma-Aldrich; Merck KGaA, at the indicated time points.

Westernblotting. Thecells werewashedwith phosphate-buffered saline (PBS) and lysed for $40 \mathrm{~min}$ at $4{ }^{\circ} \mathrm{C}$ with lysis buffer (20 mmol/1 HCl, 2.5 mmol/1 EDTA, 10\% glycerol, 0.1\% SDS, $1 \%$ Triton $\mathrm{X}-100,1 \%$ sodium deoxycholate, $10 \mathrm{mmol} / \mathrm{l}$ sodium pyrophosphate, $50 \mathrm{mmol} / 1 \mathrm{NaF}, 1 \mathrm{mmol} / 1$ sodium vanadate, $1 \mathrm{mmol} / 1$ phenylmethylsulfonyl fluoride). Subsequently, the homogenate was centrifuged at $14,000 \times \mathrm{g}$ for $20 \mathrm{~min}$ at $4^{\circ} \mathrm{C}$. The protein concentration was measured using a Bradford assay. Equal amounts of extracted protein samples $(40 \mu \mathrm{g})$ were separated by $10 \%$ SDS-PAGE and transferred to polyvinylidene fluoride membranes. The membranes were blocked with $5 \%$ dry milk for $1 \mathrm{~h}$ at $37^{\circ} \mathrm{C}$ and incubated with rabbit anti-Nox4 (14347-1-AP; 1:400 dilution; ProteinTech Group, Inc., Chicago, IL, USA), anti-Notch1 (20687-1-AP; 1:1,000 dilution; ProteinTech Group, Inc.), anti-Notch intracellular domain 1 (NICD1; 4147; 1:1,000 dilution; Cell Signaling Technology, Inc., Danvers, MA, USA), anti-phosphorylated (p)-Rac1 (2461; 1:1,000 dilution; Cell Signaling Technology, Inc.), anti-Rac1 (36,742; 1:2,000 dilution; Signalway Antibody LLC, College Park, Maryland, USA), anti-B-cell lymphoma 2 apoptosis regulator (Bcl-2; 4223; 1:1,000 dilution; Cell Signaling Technology, Inc.), anti-cleaved caspase-3 (9664; 1:1,000 dilution; Cell Signaling Technology, Inc.), anti-Bcl-2 associated protein $\mathrm{X}$ apoptosis regulator (Bax; 2772; 1:1,000 dilution; Cell Signaling Technology, Inc.) and anti- $\beta$-actin (sc-130656; 1:1,000 dilution; Santa Cruz Biotechnology, Inc., Dallas, TX, USA) polyclonal antibodies at $4^{\circ} \mathrm{C}$ overnight. The membranes were then washed and incubated with a goat anti-rabbit IgG horseradish peroxidase-conjugated secondary antibody (SA00001-2; 1:5,000 dilution; ProteinTech Group, Inc.) for $2 \mathrm{~h}$ at room temperature. The labeled bands were quantified using a UVP Image Station Lab works 4.5 (UVP Inc., Upland, CA, USA) and compared with $\beta$-actin.

\section{Reverse transcription-quantitative polymerase chain reaction} $(R T-q P C R)$ analysis. Total RNA was extracted using TRIzol ${ }^{\circledR}$ reagent (Invitrogen; Thermo Fisher Scientific, Inc.) and reverse transcribed using oligo (dT) primer (Sangon Biotech Co., Ltd., Shanghai, China) in the presence of the avian myeloblastosis virus reverse transcriptase (Takara Biotechnology Co., Ltd., Dalian, China), to produce cDNA. cDNA was amplified on the 7900HT Sequence Detection system (Applied Biosystems; Thermo Fisher Scientific, Inc.) with SYBR Premix EX Taq kit (Takara Biotechnology Co., Ltd.) at default thermal cycling conditions: $2 \mathrm{~min}$ at $50^{\circ} \mathrm{C}, 10 \mathrm{~min}$ at $95^{\circ} \mathrm{C}$ and then 40 cycles of $15 \mathrm{sec}$ at $95^{\circ} \mathrm{C}$ for denaturation and $1 \mathrm{~min}$ at $60^{\circ} \mathrm{C}$ for annealing and extension. Results were quantified using the relative standard curve method of analysis $/ \Delta \mathrm{C}_{\mathrm{q}}$ method of analysis (13), relative to $18 \mathrm{~S}$ rRNA. The oligonucleotide primer sequences were as follows: 18S, forward 5'-CGC CGC TAG AGG TGA AAT TC-3' and reverse 5'-CCA GTC GGC ATC GTT TAT GG-3'; Nox4, forward 5'-GTT GGG GCT AGG ATT GTG TCT-3' and reverse 5'-TCG GCA CAT GGG TAA AAG GA-3'; and Notch1, forward 5'-CTA AGA TCT CCT GAG GGC TTC AAA GTG TC-3' and reverse 5'-GCG AAT TCC TTG AAG GCC TCC GGA T-3'.

Intracellular ROS detection. Total ROS levels were detected using the fluorescence probe 5-(and 6) chloromethyl-2', 7'-dichlorodihydrofluorescein diacetate (CM-DCHF-DA; Invitrogen; Thermo Fisher Scientific, Inc.). HKC cells were seeded into 6-well plates at a density of $1 \times 10^{6}$ cells $/ \mathrm{ml}$ and incubated under different experimental conditions for $24 \mathrm{~h}$. The cells were washed with PBS three times, trypsinized and centrifuged at $300 \mathrm{x} \mathrm{g}$ for $5 \mathrm{~min}$ at $4^{\circ} \mathrm{C}$. The cells were then resuspended and incubated in pre-warmed PBS with $10 \mu \mathrm{M}$ DCHF-DA at $37^{\circ} \mathrm{C}$ for $30 \mathrm{~min}$ in the dark. Subsequently, cells were washed with PBS three times to remove the free DCFH-DA and fixed with $1 \%$ paraformaldehyde for $10 \mathrm{~min}$ at $4^{\circ} \mathrm{C}$. The levels of intracellular ROS were quantified using a flow cytometer (BD Biosciences, Franklin Lakes, NJ, USA) with FlowJo software version 7.6 (FlowJo LLC, Ashland, OR, USA).

Annexin V/propidium iodide (PI) staining assay. Apoptotic rates in the differing groups were detected using an Annexin V/PI staining kit (MultiSciences Biotech Co., Ltd., Hangzhou, China) according to the manufacturer's protocol. HKC cells were incubated under different experimental conditions for $24 \mathrm{~h}$, and then washed with PBS three times, trypsinized and centrifuged at $300 \mathrm{x} \mathrm{g}$ for $5 \mathrm{~min}$ at $4^{\circ} \mathrm{C}$. Cells were resuspended in $1 \mathrm{X}$ binding buffer, incubated with Annexin V-FITC and PI at room temperature for $5 \mathrm{~min}$ in the dark. Following fixation with $1 \%$ paraformaldehyde for 
A
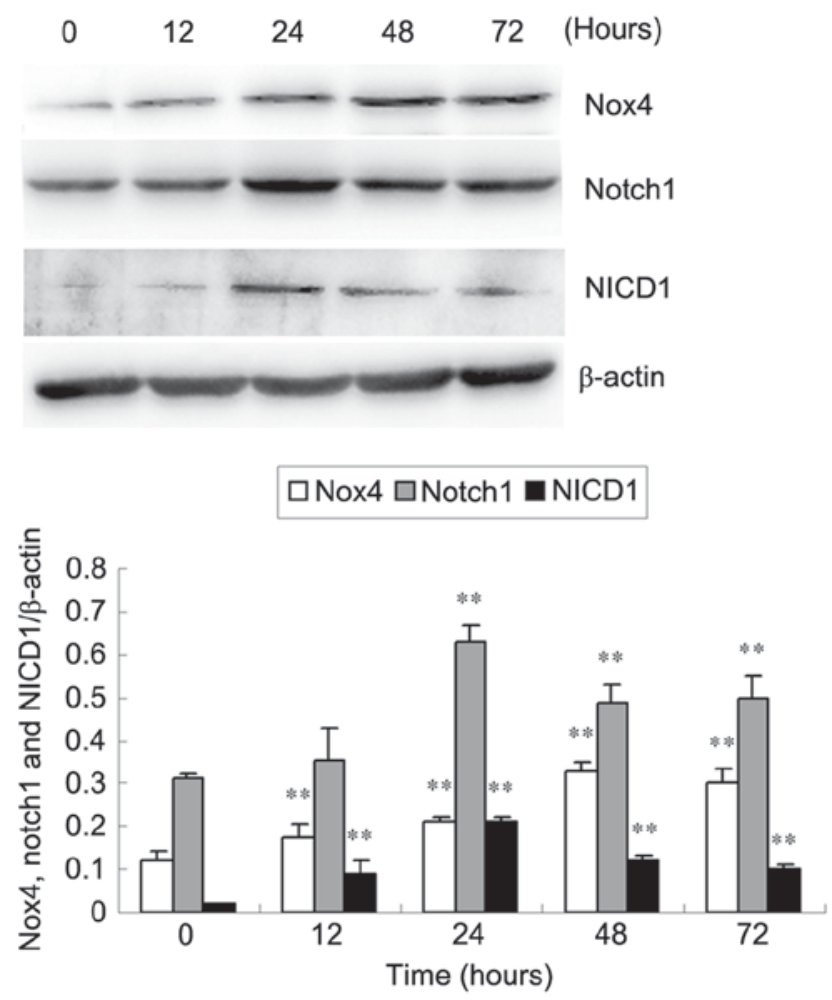

B

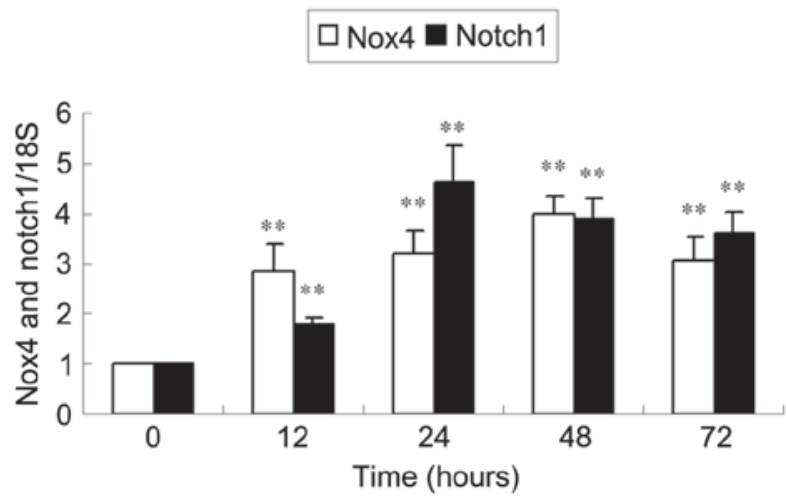

Figure 1. Expression of Nox4, Notch1 and NICD1 in HG-induced HKC cells at the different time points (0-72 h). (A) Representative images and quantification of Nox4, Notch1 and NICD1 protein expression analyzed by western blotting. (B) Nox4 and Notch1 mRNA expression was detected by reverse transcription-quantitative polymerase chain reaction relative to $18 \mathrm{~S}$ rRNA. Data are expressed as the mean + standard deviation. ${ }^{* *} \mathrm{P}<0.01$ vs. control $(0 \mathrm{~h})$. Nox 4 , nicotinamide adenine dinucleotide phosphate-oxidase oxidase 4 ; NICD1, Notch intracellular domain 1.

10 min at $4^{\circ} \mathrm{C}, \mathrm{HKC}$ cells analyzed using a flow cytometer (Epics-XLII; Beckman Coulter, Inc., Brea, CA, USA) with FlowJo software version 7.6 (FlowJo LLC).

Statistical analysis. Data are presented as the mean + standard deviation of at least three independent experiments. All data were analyzed using SPSS software version 15.0 (SPSS, Inc., Chicago, IL, USA). Differences between groups were analyzed using one-way analysis of variance followed by a post hoc Bonferroni's test for multiple comparisons. $\mathrm{P}<0.05$ was considered to indicate a statistically significant difference.

\section{Results}

$H G$ induces Nox4 and Notch pathway expression in $H K C$ cells. Western blotting and RT-qPCR analyses were used to examine HG-induced Nox4 and Notch1 protein and mRNA expression levels in HKC cells (Fig. 1). Nox4 protein and mRNA expression increased as early as $12 \mathrm{~h}$, reached a peak at $48 \mathrm{~h}$ and decreased at $72 \mathrm{~h}(\mathrm{P}<0.01$; Fig. 1). Notch1 protein and mRNA expression significantly increased at $24 \mathrm{~h}$, then decreased at 48 and $72 \mathrm{~h}(\mathrm{P}<0.01$; Fig 1). NICD1 protein expression levels reached a peak at $24 \mathrm{~h}$ compared with $0 \mathrm{~h}$ following stimulation with $\mathrm{HG}(\mathrm{P}<0.01$; Fig. 1A). Furthermore, no significant differences in Nox4, Notch1 and NICD1 expression were observed in HKC cells cultured under NG conditions among different time points (all $\mathrm{P}>0.05$; data not shown).

DAPT inhibits Notch pathway expression and cell apoptosis in HG-induced HKC cells. A significant increase in NICD1 protein expression was observed in HKC cells stimulated with $\mathrm{HG}$ for $24 \mathrm{~h}$ when compared with $\mathrm{NG}$ and this was then decreased with addition of DAPT ( $<<0.01$; Fig. 2A and B). Notch1 protein (Fig. 2A and B) and mRNA (Fig. 2C) expression was also significantly increased in HKC cells stimulated with $\mathrm{HG}$ for $24 \mathrm{~h}$ compared with $\mathrm{NG}(\mathrm{P}<0.01$; Fig. $2 \mathrm{~A}-\mathrm{C})$, however, DAPT did not inhibit Notch1 protein and mRNA overexpression induced by $\mathrm{HG}$ (P>0.05; Fig. 2A-C). HG significantly increased Bax and cleaved caspase- 3 protein levels in HKC cells compared with $\mathrm{NG}$, and simultaneously decreased Bcl-2 protein expression ( $\mathrm{P}<0.01$; Fig. $2 \mathrm{D}$ and $\mathrm{E})$. Treatment with DAPT reversed the alterations in Bax, Bcl-2 and cleaved caspase-3 protein levels in HG-induced HKC cells $(\mathrm{P}<0.01$; Fig. 2D and $\mathrm{E})$. Furthermore, the increased apoptosis rate in $\mathrm{HG} \mathrm{HKC}$ cells compared with NG cells ( $\mathrm{P}<0.01$; Fig. $2 \mathrm{~F}$ and $\mathrm{G}$ ) was reduced by treated with DAPT, as demonstrated by flow cytometry $(\mathrm{P}<0.01$ vs. HG; Fig. $2 \mathrm{~F}$ and $\mathrm{G})$.

NAC and DPI inhibit Nox4 and Notch pathway expression and ROS generation in HG-induced HKC cells. Western blotting was used to examine $\mathrm{HG}$-induced protein expression of Nox4, p-Rac1, Rac1, Notch1 and NICD1 in HKC cells after 24 h (Fig. 3A-C). HG significantly increased Nox4, Notch1 and NICD1 protein expression levels compared with $\mathrm{NG}(\mathrm{P}<0.01$; Fig. 3A and $\mathrm{B})$, but this increase was inhibited by NAC and DPI $(\mathrm{P}<0.05$ or $\mathrm{P}<0.01$; Fig. $3 \mathrm{~A}$ and $\mathrm{B})$. HG significantly increased the ratio of $\mathrm{p}-\mathrm{Rac1} / \mathrm{Racl}$ compared with NG ( $\mathrm{P}<0.01$; Fig. 3A and $\mathrm{C})$, but while this effect was inhibited by DPI ( $\mathrm{P}<0.01$ vs. HG; Fig. $3 \mathrm{~A}$ and $\mathrm{C}$ ), no effect was observed with NAC ( $P>0.05$ vs. HG; Fig. 3A and C). No alteration of total Racl expression was observed in the cultured HKC cells of different groups (Fig. 3A). RT-qPCR analysis revealed that mRNA expression of Nox4 and Notch1 in the HG-induced HKC cells significantly increased compared with NG $(\mathrm{P}<0.01$; Fig. 3D). Nox4 and Notch1 mRNA levels significantly decreased compared with $\mathrm{HG}$ in cells cultured with NAC or DPI in HG culture medium $(\mathrm{P}<0.05$ or $\mathrm{P}<0.01$; Fig. 3D). Intracellular ROS levels were observed to be increased in the HG group compared with the NG group $(\mathrm{P}<0.01$; Fig. $3 \mathrm{E})$, and this HG-induced ROS 


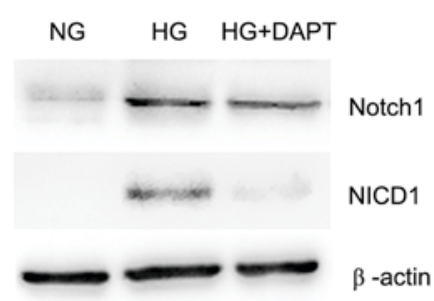

D

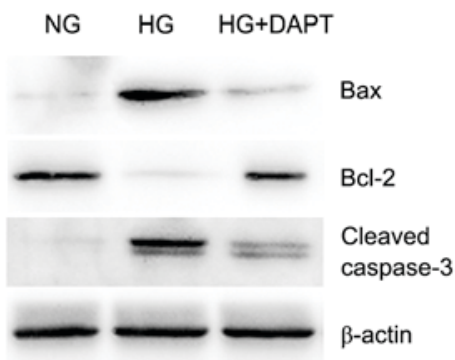

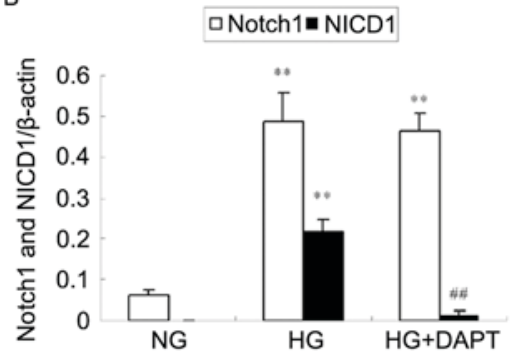

$\mathrm{E}$

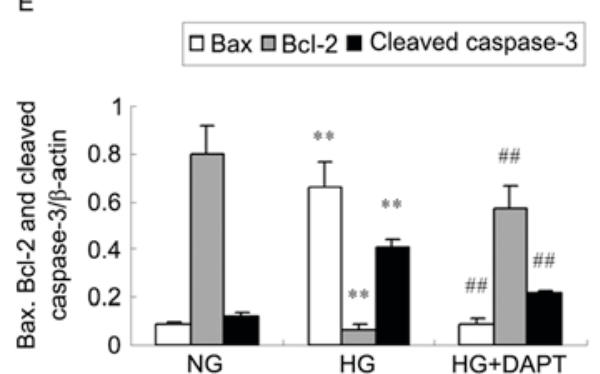

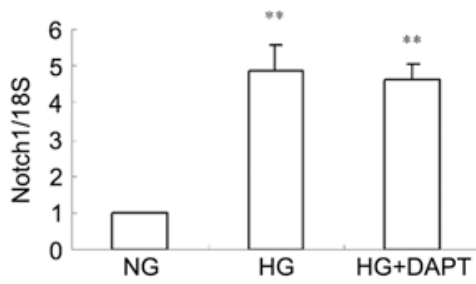

F

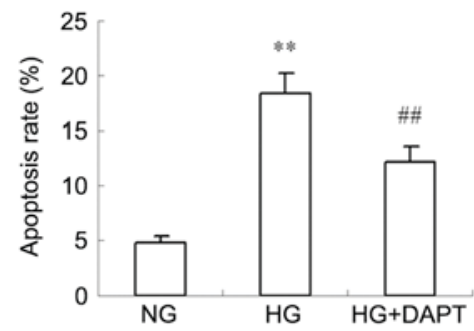

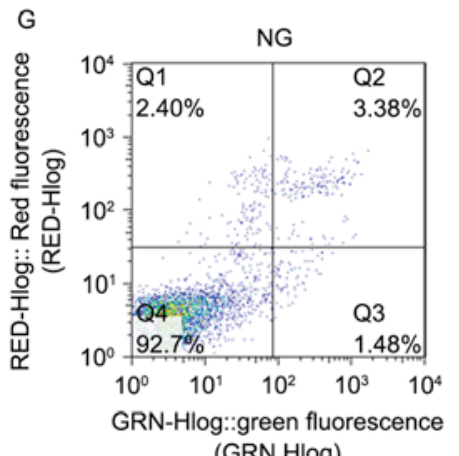
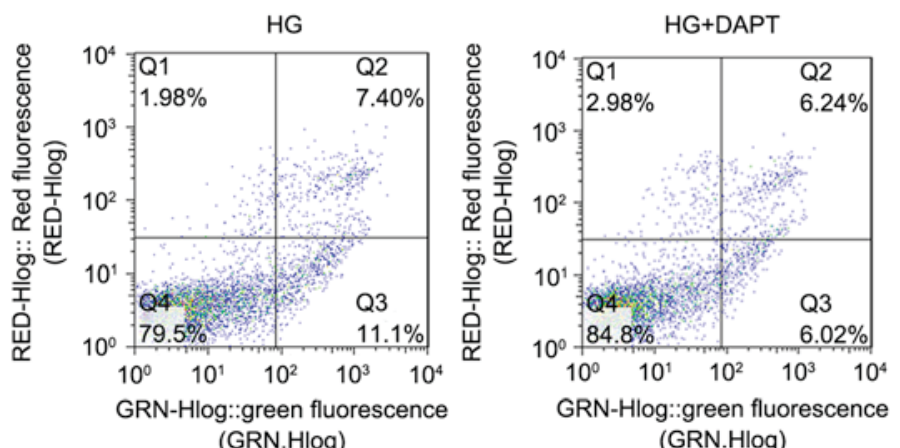

Figure 2. Effects of DAPT on HG-induced Notch pathway expression and HKC cell apoptosis. HKC cells were incubated with NG, HG or HG + DAPT for $24 \mathrm{~h}$. (A) Representative images and (B) quantification of Notch1 and NICD1 protein expression analyzed by western blotting. (C) Notch1 mRNA expression was analyzed by reverse transcription-quantitative polymerase chain reaction relative to $18 \mathrm{~S}$ rRNA. (D) Representative images and (E) quantification of Bax, Bcl-2 and cleaved caspase-3 protein expression levels analyzed by western blotting. (F) Quantification and (G) representative images and of flow cytometry analysis of HKC cells stained with Annexin V/propidium iodide. Data are expressed as the mean + standard deviation. ${ }^{* *} \mathrm{P}<0.01$ vs. NG. ${ }^{\# /} \mathrm{P}<0.01 \mathrm{vs}$. HG. NG, normal glucose; HG, high glucose; DAPT, $\gamma$-secretase inhibitor; NICD1, Notch intracellular domain 1; Bcl-2, B-cell lymphoma 2 apoptosis regulator; Bax, $\mathrm{Bcl}-2$ associated protein $\mathrm{X}$ apoptosis regulator.

production was significantly suppressed by addition of NAC or DPI ( $\mathrm{P}<0.01$ vs. HG; Fig. 3E).

NAC and DPI inhibit HG-induced HKC cell apoptosis. The protein levels of Bax and cleaved caspase-3 decreased in HKC cells treated with NAC and DPI compared with levels present in the HG group, whereas Bcl-2 protein levels increased $(\mathrm{P}<0.05$ or $\mathrm{P}<0.01$; Fig. $4 \mathrm{~A}$ and $\mathrm{B})$. HG-induced HKC cells exhibited a significantly increased apoptosis rate after $24 \mathrm{~h}$ compared with the NG cells treated $(\mathrm{P}<0.01$; Fig. 4C and D), whereas NAC and DPI efficiently inhibited HG-induced HKC cell apoptosis $(\mathrm{P}<0.01$ vs. HG; Fig. 4C and D).

\section{Discussion}

The results of the present study demonstrated that Nox4 overexpression in HG-induced HKC cells altered Notch pathway levels and induced cell apoptosis. Nox4 and
Notch pathway inhibitors prevented HG-induced HKC cell apoptosis.

Nox 4 is a constitutively active multisubunit enzyme, which acts as an oxygen sensor and generates various ROS from molecular oxygen using NADPH as the electron donor. Various studies have reported that Nox4 is the major source of ROS in kidney disease including DN, and Nox4-derived ROS are considered to mediate renal hypertrophy, increase myofibroblast activation and renal fibrosis $(6,14)$. Additionally, ROS have been revealed to increase in the presence of $\mathrm{HG}$ via activation of NADPH oxidases $(15,16)$. The present study demonstrated that Nox4 protein and mRNA expression increased as early as $12 \mathrm{~h}$ and reached a peak at $48 \mathrm{~h}$ following stimulation with HG. HG notably increased the levels of Nox4 and Rac1 phosphorylation, which were inhibited by the antioxidant NAC and Nox inhibitor DPI. Hyperglycemia in renal proximal tubule cells may activate Nox and produce superoxide anion and hydrogen peroxide, which may be reversed by treatment with DPI, resulting in an increase in 


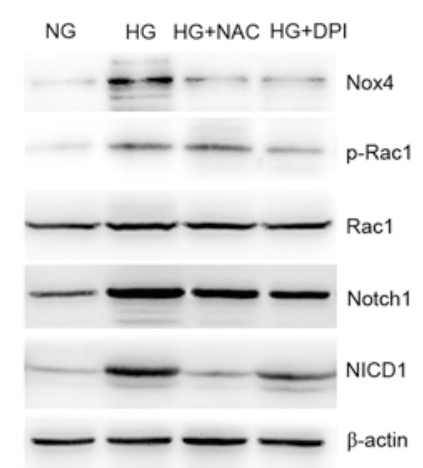

B

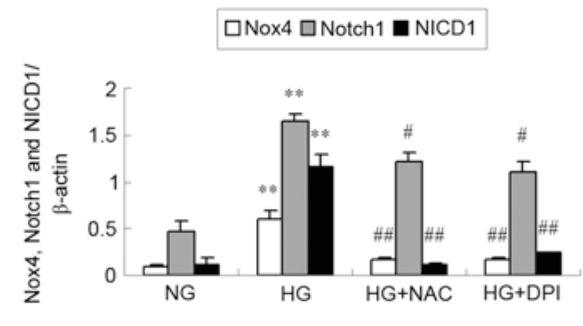

D

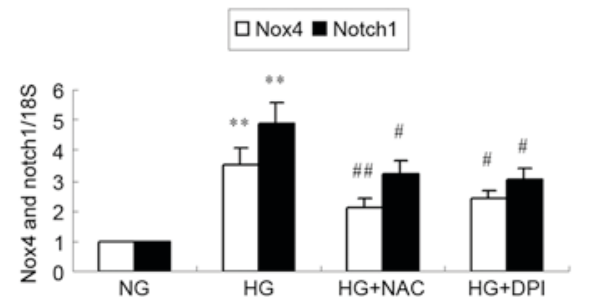

C

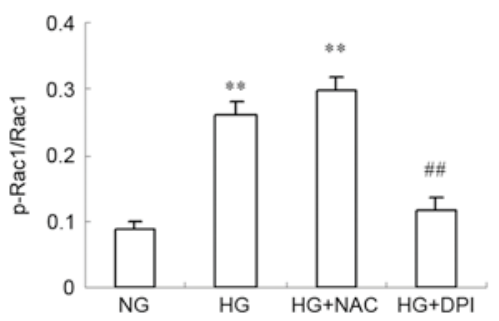

E

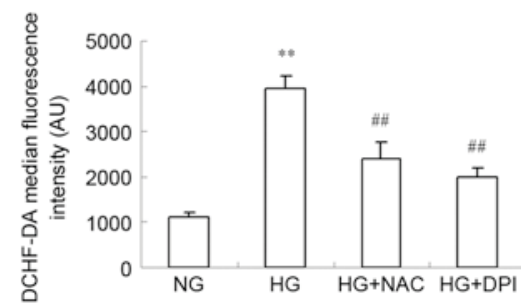

Figure 3. Effects of NAC and DPI on HG-induced Nox4 and Notch pathway expression and ROS generation in HKC cells. HKC cells were incubated with NG, HG, HG + NAC or HG + DPI for 24 h. (A) Representative image of Nox4, p-Rac1, Rac1, Notch1 and NICD1 protein expression levels analyzed by western blotting. Quantification of (B) Nox4, Notch1, NICD1 relative to $\beta$-actin and (C) relative p-Rac1/Rac1 expression levels. (D) Nox4 and Notch1 mRNA expression was analyzed by reverse transcription-quantitative polymerase chain reaction relative to $18 \mathrm{~S}$ rRNA. (E) Quantitative analysis of DCHF-DA fluorescence intensity using flow cytometry. Data were expressed as the mean + standard deviation. ${ }^{* *} \mathrm{P}<0.01$ vs. NG. ${ }^{~} \mathrm{P}<0.05$ and ${ }^{\# \prime} \mathrm{P}<0.01$ vs. HG. NAC, N-acetylcysteine; DPI, diphenylene iodonium; HG, high glucose; Nox 4, nicotinamide adenine dinucleotide phosphate-oxidase (NADPH) oxidase 4; ROS, reactive oxygen species; NG, normal glucose; p, phosphorylated; Rac 1, Ras-related C3 botulinum toxin substrate 1; NICD1, Notch intracellular domain 1; DCHF-DA, dichlorodihydrofluorescein diacetate.
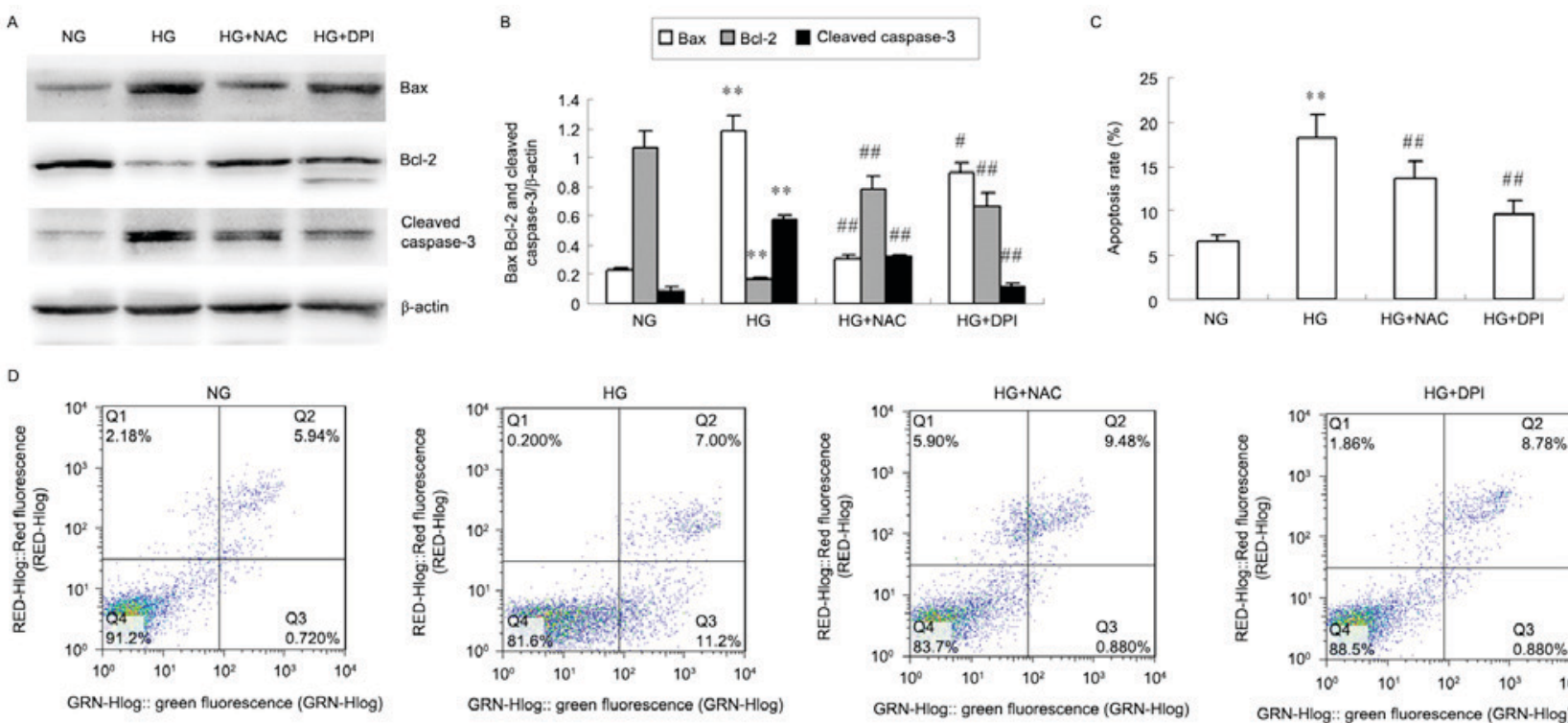

Figure 4. Effects of NAC and DPI on HG-induced HKC cell apoptosis. HKC cells were incubated with NG, HG, HG + NAC or HG + DPI for $24 \mathrm{~h}$. (A) Representative images and (B) quantification of Bax, Bcl-2 and cleaved caspase-3 protein expression levels were analyzed by western blotting relative to $\beta$-actin. (C) Quantification and (D) representative images of flow cytometric analysis of HKC cells stained with Annexin V/propidium iodide. Data were expressed as the mean + standard deviation. ${ }^{* *} \mathrm{P}<0.01$ vs. NG. ${ }^{~} \mathrm{P}<0.05$ and ${ }^{\# \#} \mathrm{P}<0.01$ vs. HG. NAC, N-acetylcysteine; DPI, diphenylene iodonium; HG, high glucose; NG, normal glucose; Bcl-2, B-cell lymphoma 2 apoptosis regulator; Bax, Bcl-2 associated protein $\mathrm{X}$ apoptosis regulator.

TGF- $\beta 1$ secretion and the activation of the nuclear factor (NF)- $\mathrm{BB}$ signal transduction pathway (17). It has additionally been demonstrated that Angiotensin II-induced activation of mitochondrial Nox4 is an important endogenous source of ROS and is associated with cell survival in kidney tubular cells (18).

The Notch pathway is an evolutionarily conserved signaling pathway, which participates in a variety of cellular processes and is important in kidney development (19). Cheng et al (20) observed Notch1 activation in the comma-shaped and S-shaped bodies during kidney development. Following inhibition of the Notch pathway, fewer renal epithelial structures are observed, with a severe deficiency in proximal tubules and podocytes, accompanied by an increase in intervening, nonepithelial cells. Notch expression is enhanced in the tubule cells of fibrotic kidneys 
from diabetic mice and humans and Notch interacting proteins have been identified that may be pertinent in normal and pathological functioning (21). The present study additionally demonstrated that HG activated the Notch pathway in a time-dependent manner in HKC cells and the maximum expression of Notch1 and NICD1 was observed at 24 h. HG increases Notch1 expression and releases NICD1, which travels into the nucleus and activates the downstream genes in HKC cells $(22,23)$. DAPT, a Notch pathway inhibitor, suppresses activation of the Notch pathway by HG, which may inhibit $\gamma$-secretase-mediated proteolytic cleavage of Notch, reducing the release of the NICD from the plasma membrane into the nucleus (10). DAPT inhibited NICD1 expression and did not reduce Notch1 protein and mRNA overexpression in HG-induced HKC cells. DAPT additionally reduced the ratio of $\mathrm{Bax} / \mathrm{Bcl}-2$ and cleaved caspase-3 expression in HG-induced HKC cells. Flow cytometry demonstrated that $\mathrm{HG}$ induced $\mathrm{HKC}$ cell apoptosis, which was subsequently inhibited by treatment with DAPT. These results indicated that HG induced HKC cell apoptosis through activation of the Notch pathway. Notch pathway activity has additionally been revealed to participate in puromycin aminonucleoside-induced renal proximal tubular cell apoptosis via caspase-3 (24). The Notch signaling pathway is important in renal ischemia/reperfusion (I/R), inducing severe tubular damage and resulting in increased $\mathrm{NF}-\kappa \mathrm{B}, \mathrm{Bax}$ and tubular cell apoptosis and reduced $\mathrm{Bcl}-2$ expression (25).

The present study then used the chemical inhibitors NAC and DPI to investigate if Nox4 mediated HKC cell apoptosis via regulation of the Notch pathway in HG medium. HG notably increased levels of Nox4 and Rac1 phosphorylation, which were inhibited by NAC and DPI. Similarly, NAC and DPI inhibited production of ROS and activation of the Notch pathway in HG-induced HKC cells. Treatment with NAC and DPI decreased the ratio of Bax:Bcl-2, reduced cleaved caspase-3 levels and HKC cell apoptosis following HG stimulation. Therefore, HG-induced Nox4 overexpression in HKC cells induced cell apoptosis via activation of the Notch pathway. Similarly, it was previously demonstrated that Rac1 regulates Notch in mediating cerebral I/R-induced production of injurious ROS and cell death in vitro and in vivo (26). HKC cell apoptosis may lead to a decrease in the number of renal tubular epithelial cells, resulting in renal interstitial fibrosis and the development of DN (27). Inhibition of Nox4 may therefore exhibit the potential to treat DN.

In conclusion, the present results indicated that $\mathrm{HG}$ caused the overexpression of Nox4 and Notch signaling molecules in HKC cells. Nox4 upregulation may serve an important role in HG-induced HKC cell apoptosis, through the activation of the Notch pathway. In addition, the present study demonstrated that the blockade of Nox 4 using a chemical inhibitor suppressed HG-induced HKC cell apoptosis. Since Nox4 is involved in renal tubular epithelial cell injury in DN, targeting Nox4 may have potential as an alternative therapeutic strategy for the treatment of patients with DN. Further studies are required to explore the molecular mechanisms underlying the involvement of Nox4 in the development of DN, including the relations between Nox4 and other signaling pathways, such as the p38 pathway.

\section{Acknowledgements}

The present study was supported by the Hebei Natural Science Foundation of China (grant no. H2014206294).

\section{References}

1. Shah A, Xia L, Masson EA, Gui C, Momen A, Shikatani EA, Husain M, Quaggin S, John R and Fantus IG: Thioredoxin-interacting protein deficiency protects against diabetic nephropathy. J Am Soc Nephrol 26: 2963-2977, 2015.

2. Al-Kafaji G, Sabry MA and Skrypnyk C: Time-course effect of high-glucose-induced reactive oxygen species on mitochondrial biogenesis and function in human renal mesangial cells. Cell Biol Int 40: 36-48, 2016.

3. Hou Y, Wu M, Wei J, Ren Y, Du C, Wu H, Li Y and Shi Y: CD36 is involved in high glucose-induced epithelial to mesenchymal transition in renal tubular epithelial cells. Biochem Biophys Res Commun 468: 281-286, 2015.

4. Brown DI and Griendling KK: Nox proteins in signal transduction. Free Radic Biol Med 47: 1239-1253, 2009

5. Holterman CE, Read NC and Kennedy CR: Nox and renal disease. Clin Sci (Lond) 128: 465-481, 2015.

6. Krause KH: Tissue distribution and putative physiological function of NOX family NADPH oxidases. Jpn J Infect Dis 57: S28-S29, 2004

7. Juillerat-Jeanneret L, Flohr A, Schneider M, Walter I, Wyss JC, Kumar R, Golshayan D and Aebi JD: Targeted $\gamma$-secretase inhibition to control the Notch pathway in renal diseases. J Med Chem 58: 8097-8109, 2015.

8. Mertens PR, Raffetseder U and Rauen T: Notch receptors: A new target in glomerular diseases. Nephrol Dial Transplant 23: 2743-2745, 2008.

9. Ji X, Wang Z, Geamanu A, Sarkar FH and Gupta SV: Inhibition of cell growth and induction of apoptosis in non-small cell lung cancer cells by delta-tocotrienol is associated with notch-1 down-regulation. J Cell Biochem 112: 2773-2783, 2011.

10. McCright B: Notch signaling in kidney development. Curr Opin Nephrol Hypertens 12: 5-10, 2003.

11. Yan F, Wang Y, Wu X, Peshavariya HM, Dusting GJ, Zhang M and Jiang F: Nox4 and redox signaling mediate TGF- $\beta$-induced endothelial cell apoptosis and phenotypic switch. Cell Death Dis 5: e1010, 2014.

12. Dang J, Jia R, Tu Y, Xiao S and Ding G: Erythropoietin prevents reactive oxygen species generation and renal tubular cell apoptosis at high glucose level. Biomed Pharmacother 64: 681-685, 2010.

13. Livak KJ and Schmittgen TD: Analysis of relative gene expression data using real-time quantitative PCR and the 2(-Delta Delta C(T)) method. Methods 25: 402-408, 2001.

14. Bondi CD, Manickam N, Lee DY, Block K, Gorin Y, Abboud HE and Barnes JL: NAD(P)H oxidase mediates TGF-beta1-induced activation of kidney myofibroblasts. J Am Soc Nephrol 21: 93-102, 2010.

15. Giacco F and Brownlee M: Oxidative stress and diabetic complications. Circ Res 107: 1058-1070, 2010.

16. Eid AA, Gorin Y, Fagg BM, Maalouf R, Barnes JL, Block K and Abboud HE: Mechanisms of podocyte injury in diabetes: Role of cytochrome P450 and NADPH oxidases. Diabetes 58: 1201-1211, 2009.

17. Han HJ, Lee YJ, Park SH, Lee JH and Taub M: High glucose-induced oxidative stress inhibits $\mathrm{Na}+$ /glucose cotransporter activity in renal proximal tubule cells. Am J Physiol Renal Physiol 288: F988-F996, 2005.

18. Kim SM, Kim YG, Jeong KH, Lee SH, Lee TW, Ihm CG and Moon JY: Angiotensin II-induced mitochondrial Nox4 is a major endogenous source of oxidative stress in kidney tubular cells. PLoS One 7: e39739, 2012.

19. Cheng HT,Kim M,Valerius MT,Surendran K, Schuster-Gossler K, Gossler A, McMahon AP and Kopan R: Notch2, but not Notch1, is required for proximal fate acquisition in the mammalian nephron. Development 134: 801-811, 2007.

20. Cheng HT and Kopan R: The role of Notch signaling in specification of podocyte and proximal tubules within the developing mouse kidney. Kidney Int 68: 1951-1952, 2005. 
21. Cummins TD, Mendenhall MD, Lowry MN, Korte EA, Barati MT, Khundmiri SJ, Salyer SA, Klein JB and Powell DW: Elongin $\mathrm{C}$ is a mediator of Notch 4 activity in human renal tubule cells. Biochim Biophys Acta 1814: 1748-1757, 2011.

22. Graziani I, Eliasz S, De Marco MA, Chen Y, Pass HI, De May RM, Strack PR, Miele L and Bocchetta M: Opposite effects of Notch-1 and Notch-2 on mesothelioma cell survival under hypoxia are exerted through the Akt pathway. Cancer Res 68: 9678-9685, 2008

23. Guo H, Lu Y, Wang J, Liu X, Keller ET, Liu Q, Zhou Q and Zhang J: Targeting the Notch signaling pathway in cancer therapeutics. Thorac Cancer 5: 473-486, 2014.

24. Ding X, Zhu F, Li T, Zhou Q, Hou FF and Nie J: Numb protects renal proximal tubular cells from puromycin aminonucleoside-induced apoptosis through inhibiting Notch signaling pathway. Int J Biol Sci 7: 269-278, 2011.
25. Huang R, Zhou Q, Veeraragoo P, Yu H and Xiao Z: Notch2/Hes-1 pathway plays an important role in renal ischemia and reperfusion injury-associated inflammation and apoptosis and the $\gamma$-secretase inhibitor DAPT has anephroprotective effect. Ren Fail 33: 207-216, 2011.

26. Meng S, Su Z, Liu Z, Wang N and Wang Z: Racl contributes to cerebral ischemia reperfusion-induced injury in mice by regulation of Notch2. Neuroscience 306: 100-114, 2015.

27. Habib SL: Diabetes and renal tubular cell apoptosis. World J Diabetes 4: 27-30, 2013. 